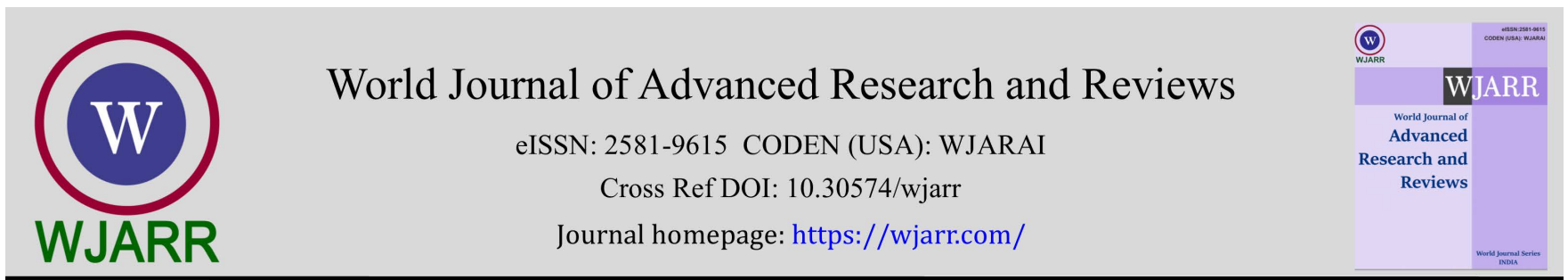

(RESEARCH ARTiClE)

Check for updates

\title{
Relationship between skin structure and wool traits for Ultrafine and Dohne Merino sheep of Uruguay
}

\author{
Vallejo Adriana 1, *, Fernández Abella Daniel 2, Ramos Zully ${ }^{3}$ and Montossi Fabio ${ }^{3}$ \\ ${ }^{1}$ Department of Animal Production and Pastures. Faculty of Agronomy, University of Uruguay (UDELAR), Montevideo, \\ Uruguay. \\ ${ }^{2}$ Department of Biological Science, Pole of Production \& Reproduction in Ruminants, University of Uruguay, Salto, Uruguay. \\ ${ }^{3}$ Meat \& Wool Research Program. Tacuarembó Experimental Station. National Agricultural Research Institute (INIA), \\ Uruguay.
}

World Journal of Advanced Research and Reviews, 2021, 12(01), 465-472

Publication history: Received on 21 September 2021; revised on 24 October 2021; accepted on 26 October 2021

Article DOI: https://doi.org/10.30574/wjarr.2021.12.1.0553

\begin{abstract}
The demand in the world market for high quality fine and superfine wool is increasing, responding to greater wool textile industry demands and price incentives. There are few research studies focused on hair follicle population in fine and superfine Merino sheep in Uruguay. This study evaluates the association between wool follicle population and the most relevant economical wool traits. This work was carried out on Ultrafine Australian Merino (UAM) and Dohne Merino (DM) animals (lambs and rams). Phenotypic correlations between the secondary/primary follicles (S/P) and other wool traits (fiber diameter, staple length, clean fleece weight, scoured yield, coefficient of variation of fiber diameter and comfort factor parameter, were performed using histological skin cuts. Two skin samples were extracted from each lamb at two and nine months of age. These were processed at the skin histology laboratory to obtain a histological preparation for further biopsy, being able to differentiate the structures obtained to be evaluated. The results showed in the UAM group, S/P ratio in nine-month-old lambs was greater than two-month-old lambs (31.08 vs $23.12 \mathrm{P}<0.05)$. For DM group, there were no differences in the $\mathrm{S} / \mathrm{P}$ ratio between age groups. Phenotypic correlations for wool characteristics obtained were of low to medium or null magnitude in both genotypes.
\end{abstract}

Keywords: Fine wools; Superfine wools; Hair follicles; S/P ratio; Wool traits

\section{Introduction}

During the last 20 years, sheep numbers have been reduced in the main wool producing countries: Australia, New Zealand, Uruguay, South Africa, and Argentina. Despite individual factors, the reasons of this decline have common patterns, mainly the price of wool accompanied with other (consumer trends, competitiveness of alternative textile fibers). On the other hand, since 1990 the evolution of the fine, superfine and ultrafine wool price has been positive, despite the high levels of volatility between years. In Uruguay, the reduction in sheep population was largely due to the micron profile and price production costs and profitable alternative to sheep farming such as forestry, cropping and beef production. This reduction has also been accompanied by changes in the sheep population's distribution, which currently is mostly limited to the northern and eastern regions and shallow soils $[1,2]$.

Twenty years ago in Uruguay, more than $70 \%$ of the main sheep breeds produced mainly $>26 \mu$ m fibers, which presented limitations for adding value and achieve price premiums [3]. In this context in 1998, the Fine Merino Genetic Nucleus (NMF) of the Research Unit of "Glencoe" (INIA Tacuarembó Research Station) was created, which in turn after

\footnotetext{
${ }^{*}$ Corresponding author: Vallejo A

Department of Animal Production and Pastures. Faculty of Agronomy, University of Uruguay, Montevideo, Uruguay. 
15 year advanced to the foundation of the Ultrafine Merino Genetic Nucleus (UAMN) of the Regional Ultrafine Wool Innovation Consortium of Uruguay (CRILU) [2].

The Dohne Merino (DM) breed was created in South Africa, to produce fine wool and meat in harsh environments. This selection process started in the late 1930's by the South African Department of Agriculture [4]. It was developed by interbreeding Peppin-style Merino ewes and German Mutton Merino rams. In 2002 the DM was introduced in Uruguay with the objective of improving the competitiveness of traditional dual purpose breeds, through enhancing meat production and carcass meat quality and promoting fine wool [5].

This study aims to evaluate the association between skin follicle characteristics (follicular density and S/P ratio) and the most relevant economical wool traits in two different genetic selection nucleus (Ultrafine Australian Merino and Dohne Merino) of Uruguay.

It is known that there is an association between lower FD and higher follicular population which accompanies an increase in follicular density. There are no published data at the moment in the country, in relation to this for both Superfine Merino and Dohne Merino.

\section{Material and methods}

\subsection{Location, period, and animals}

The experiment was carried out at the "Glencoe” Experimental Unit of INIA Tacuarembó (INIA) (latitude 32011'32”S,

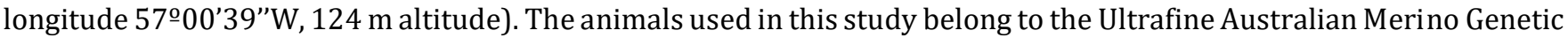
Nucleus (UAMN) of CRILU [6] and the Dohne Merino Genetic Nucleus (DMN) of INIA Tacuarembó [5]. The experimental procedures were carried out according to the recommendations set by the Uruguayan Honorary Animal Ethics Committee (protocol ID CHEA 574).

Thirty UAMN ewes were selected according to their fiber diameter (finer than $16 \pm 0.5$ microns greasy fleece weight 4 $\pm 2.7 \mathrm{~kg} /$ animal on average) and body weight. The genetic and phenotype information of rams used as well as the offspring 2015 (23 lambs UAM, males and females) for both genotypes were utilized. The parent rams used were three for each genotype where a similar number of lambs. Thirty DM ewes were used with DM parents both with known wool data. Offspring 2015 where was 20 lambs DM (males and females).

\subsection{Animal measurements}

At the beginning of the experiment, skin samples from two-month-old lambs and sires were extracted following the procedure described by Carter and Clarke [7]. Skin samples (trephine) were taken from the right mid-flank position of each animal utilizing a circular blade $1.0 \mathrm{~cm}$ diameter. Biopsy samples were placed in a fixing solution (10\% commercial formalin).For the preparation of tissue sections, different staining with specific dyes and quantitative measurement of tissue structures were performed according to established protocol $[7,8,9]$.The processing of the skin for histological study was carried out as described by Maddocks and Jackson, [8], including the additional modifications suggested by DILAVE Laboratory (Ministry of Livestock, Agriculture and Fishery) [10]. A second skin sample was extracted from each lamb at nine months of age.

Follicular population counting was recorded by an Olympus BX 41 SERIES riddle connected to a computer with image analysis software [11]. The total number of primary follicles (P) was obtained by recognizing accessory structures (sweat gland, blobbed sebaceous gland, pili-erector muscle) and by the position of the follicular group, whereas the secondary follicles (S) were identified by the presence of unique accessory structure (unilobulated sebaceous gland). Follicles with and without fiber and derived (branched) were also determined. Figure 1 shows the histological cut of sheepskin and its different sctructures seen under microscope [12].

Prior to shearing mid-side fleece samples were taken and tested for fiber diameter (FD, $\mu \mathrm{m})$, coefficient of variation of diameter (CVFD, \%), comfort factor (CF; \% fibers $>30 \mu \mathrm{m}$ ), scoured yield (SY, \%) and staple length (SL, cm) as described by Ramos et al, 2019 and 2021 [13]. At shearing individual fleeces were weighed (GFW, kg). 


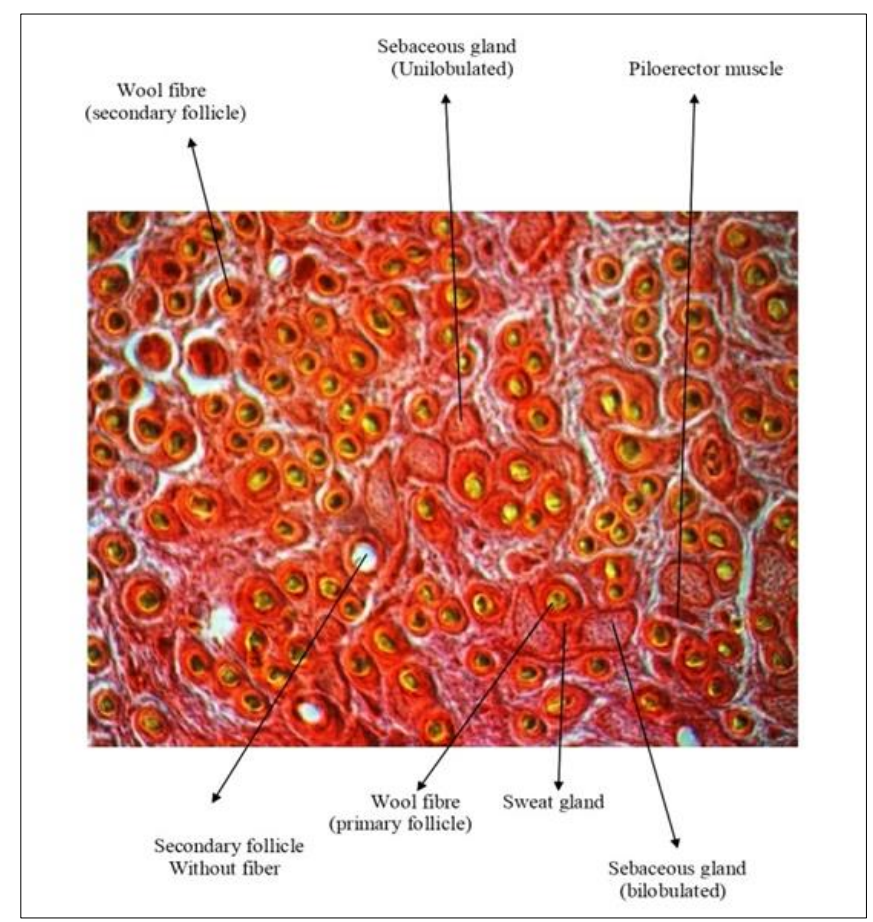

Figure 1 Histological cut of sheepskin seen under the microscope

\subsection{Statistical Analysis}

Data were analysed utilizing a general linear mixed model of the statistical package Info stat (Group Info Stat Professional). The model for wool traits included "genotype" as fixed effect and "Sire" nested "within breed" and "dams of the lamb" as a random effects. The regression coefficient for the covariate age was adjusted for date of birth and sex. In those cases where the covariate was not significant, it was eliminated from the model. Means were compared with the LSD test since in all cases 2 means were compared. Correlations between the S/P ratio and wool traits were studied using Pearson's correlation coefficient. To calculate the correlations, the residuals were obtained from a model in which the effect of date of birth and sex were considered, so that the correlation considered the variable adjusted for these factors.

Significant differences and mean comparisons were performed using Tukey's probability pair wise tests. Significant effects were declared at $\mathrm{p}<0.05$. Pearson's correlation coefficients between wool quality traits were also estimated.

\section{Results and discussion}

\subsection{UAM Lambs}

Table 1 Fibre diameter (FD, $\mu \mathrm{m}$ ) and S/P ratio of sires and lambs in Ultrafine Australian Merino Nucleus

\begin{tabular}{|c|c|c|c|c|c|c|c|}
\hline \multicolumn{3}{|c|}{ Sires } & \multicolumn{4}{|c|}{ Lambs } & \multirow{2}{*}{$\begin{array}{c}S / P \\
\text { ratio increment } \\
2 \text { to } 9 \text { months } \\
\text { (\%) }\end{array}$} \\
\hline ID & $\begin{array}{c}\text { FD } \\
(\mu \mathrm{m})\end{array}$ & S/P Ratio & N/lambs & $\begin{array}{c}\text { FD } \\
(\mu \mathrm{m})\end{array}$ & $\begin{array}{c}\mathrm{S} / \mathrm{P} \\
\text { ratio } \\
\text { at } 2 \text { months }\end{array}$ & $\begin{array}{c}\mathrm{S} / \mathrm{P} \\
\text { ratio } \\
\text { at } 9 \text { months }\end{array}$ & \\
\hline 11213 & 15.1 & 30.0 & 8 & 15.1 & 22.4 & 33.6 & 50.1 \\
\hline 12186 & 15.7 & 24.0 & 7 & 15.4 & 22.2 & 28.9 & 35.3 \\
\hline 12267 & 15.2 & 31.6 & 7 & 14.2 & 25.9 & 32.4 & 24.7 \\
\hline 17263* & - & - & 1 & 14.2 & 21.8 & 23.2 & 6.7 \\
\hline Average & 15.3 & 31.4 & 23 & 14.6 & 23.4 & 31.4 & 34.2 \\
\hline
\end{tabular}


FD is similar in sires and lambs, S/P ratio is variable between lambs, increasing significantly $(\mathrm{p}<0.05)$ between two and nine months. These values are similar to those reported previously by the literature for UAMN $[14,15,16,17,18]$.

Table 2 Phenotypic correlations between the S/P ratio and wool traits

\begin{tabular}{|l|c|c|}
\hline & $\mathbf{S} / \mathbf{P}$ & \\
\hline Trait & $\mathbf{r}$ & $\mathbf{p}$ \\
\hline FW & -0.06 & 0.78 \\
\hline FD & -0.26 & 0.23 \\
\hline CVD & -0.22 & 0.32 \\
\hline CF & -0.12 & 0.58 \\
\hline CFY & -0.18 & 0.42 \\
\hline SL & -0.37 & 0.08 \\
\hline
\end{tabular}

There is a tendency $(\mathrm{p}=0.08)$ to reduce the staple length when S/P ratio is increased. This is explained by follicular competition for nutrients $[19,20]$. In the rest of the variables, a negative relationship is observed but no significant correlations were obtained. This can be explained by the number of animals and the observed variability.

A positive correlation was obtained between fleece weight and both fiber diameter $(r=0.43, p=0.04)$, and staple length $(\mathrm{r}=0.65, \mathrm{p}=0.0007)$. In the case of diameter the correlation was average. This coincides with Turner and Young, 1969 [21], reported moderate correlations which indicate high correlations for Strong Merino and mean correlations for Medium and Fine Merino.

FD shows a high positive relationship with SL ( $\mathrm{r}=0.56, \mathrm{p}=0005)$, which does not match the literature. This can be explained by the selection made on the FW trait, which by not increasing the number of follicles per skin area would increase the other component that is the efficiency of conversion into fiber, the staple length [22,23].

The increase in the diameter of the fibers determine an increase in the variability of the fibers $(r=-0.40, p=0.05)$ as reported by Chapman [24]. The variability of the diameter is greater than the length of the fibers $(r=42, p=0.04)$, determining an increase in the length and thus an increase in variation [25].

\subsection{DM Lambs}

Table 3 Diameter and S/P ratio of sires and lambs in Dohne Merino Nucleus

\begin{tabular}{|c|c|c|c|c|c|c|c|}
\hline \multicolumn{3}{|c|}{ Sires } & \multicolumn{4}{|c|}{ Lambs } & \multirow{2}{*}{$\begin{array}{l}\mathrm{S} / \mathrm{P} \\
\text { ratio increment } \\
2 \text { to } 9 \text { months } \\
(\%)\end{array}$} \\
\hline ID & $\begin{array}{c}\text { FD } \\
(\mu \mathrm{m})\end{array}$ & $\begin{array}{c}\text { S/P } \\
\text { Ratio }\end{array}$ & N/lambs & $\begin{array}{c}\text { FD } \\
(\mu \mathrm{m})\end{array}$ & $\begin{array}{c}\text { S/P } \\
\text { Ratio } \\
\text { at } 2 \text { months }\end{array}$ & $\begin{array}{c}\text { S/P } \\
\text { Ratio } \\
\text { at } 9 \text { months }\end{array}$ & \\
\hline 30016 & 19.3 & 20.7 & 2 & 17.9 & 20.7 & 26.6 & 23.6 \\
\hline 31009 & 19.5 & 23.6 & 1 & 19.8 & 20.9 & 20.6 & -0.0 \\
\hline 39038 & 21.3 & 22.7 & 4 & 18.2 & 21.2 & 22.7 & 7.3 \\
\hline CA3807* & $\ldots$ & $\cdots$ & 5 & 18.1 & 20.9 & 23.9 & 14.3 \\
\hline $32024^{*}$ & $\ldots$ & $\ldots$ & 7 & 18.9 & 20.1 & 22.4 & 11.8 \\
\hline $44440^{*}$ & $\ldots$ & $\ldots$ & 1 & 19.1 & 19.4 & 19.4 & 11.0 \\
\hline Average & 20.0 & 22.4 & 20 & 19.4 & 20.6 & 22.9 & 11.2 \\
\hline
\end{tabular}


Sires' FD is superior to that observed in the lambs (Table 3). S/P ratio is variable between lambs, increasing by $11 \%$ from two to nine months. The values of S/P ratio for DMN are the first reported, there are no previous works in the literature on the follicular population of this breed.

Negative tendencies are observed between the S/P ratio and the diameter of fiber and the percentage of fibers greater than 30 microns. No further significant differences were found in the rest of the variables evaluated. These results are consistent with the bibliography, indicating that finer fiber diameters promote lower percentage of fibers greater than 30 microns $[14,15,22$, and 23].

Table 4 Phenotypic correlations between the S/P ratio and wool traits

\begin{tabular}{|l|c|c|}
\hline Trait & $\mathbf{r}$ & $\mathbf{p}$ \\
\hline FW & 0.23 & 0.35 \\
\hline FD & -0.39 & 0.10 \\
\hline CVD & 0.01 & 0.98 \\
\hline CF & -0.40 & 0.09 \\
\hline CFY & 0.22 & 0.39 \\
\hline SL & -0.16 & 0.51 \\
\hline
\end{tabular}

The increase in the number of fibers greater than 30 microns is associated with an increase in FD ( $r=0.59, \mathrm{p}=0.01)$ and a greater CVD ( $\mathrm{r}=0.61, \mathrm{p}=0.008)$ in accordance with other experimental results reported in the literature [14, 15, 21, 23, $25,26]$. In this genotype, CFY is positively affected with SL ( $r=0.48, p=0.04)$ and negatively (tendency) with CVD ( $\mathrm{r}=-$ $0.41, \mathrm{p}=0.09$ ).

Table $5 \mathrm{~S} / \mathrm{P}$ ratio in both genotypes at 2 and 9 months of age

\begin{tabular}{|l|c|l|c|c|}
\hline Breed(genotype) & 2 months & & 9 months & \\
\hline UAMN & $23.12+1.20$ & B b & $31.08+1.20$ & A b \\
\hline DMN & $20.28+1.29$ & B b & $22.63+1.29$ & B b \\
\hline
\end{tabular}

The S/P ratio shows a significant difference within the UAMN genotype between two to nine months, but none in the case of DMN or when genotypes are compared. The S/P ratios felt within the range found by Reis [28], which reported for fine Merino values of S/P ratio of 20-27 for fiber between 16-21 microns. In this work, the average FDs for UAMN and DMN are 14.6 and $19.4 \mu \mathrm{m}$, respectively. The increase in the S/P ratio in the UAM is explained by the second wave of maturation of the secondary follicles as described by Chapman [24].

Table 6 Percentage of follicles derived for both genotypes at 2 and 9 months of age

\begin{tabular}{|l|l|l|l|c|}
\hline Breed(genotype) & 2 months & & 9 months & \\
\hline UAMN & $11.26 \pm 1.03$ & $\mathrm{~A}$ & $10.86 \pm 1.03$ & $\mathrm{~A}$ \\
\hline DMN & $8.73 \pm 1.11$ & $\mathrm{~B} \mathrm{~b}$ & $10.71 \pm 1.11$ & $\mathrm{~B} \mathrm{~b}$ \\
\hline
\end{tabular}

No significant differences were found in derived secondary follicles percentage measurements between genotypes, nor were significant differences found in two and nine month measurements in each genotype. Several studies have shown that wool growth and fiber dimensions are substantially altered as sheep age increases [27]. Variations in the percentage of derived secondary follicles do not increase as the original secondary follicles increase but they are compensated with smaller amounts. In relation to follicular density, no significant differences were found in the UAMN between two and nine months as well as between genotypes. Significant differences were found in follicular density between two and nine months of again the DMN genotype. 
Table 7 Follicular density for 2 genotypes at 2 and 9 months of age

\begin{tabular}{|c|l|l|l|l|}
\hline Breed(genotype) & \multicolumn{2}{|l|}{ months } & \multicolumn{2}{l|}{ months } \\
\hline UAMN & $140.79 \pm 9.14$ & Aa & $143.06 \pm 9.14$ & A a \\
\hline DMN & $146.26 \pm 9.96$ & Aa & $125.60 \pm 9.96$ & A b \\
\hline
\end{tabular}

Follicular density is explained in the UAMN by the second wave of maturation. In contrast, follicular regression is observed in DMN probability due to poor follicle nutrition due to high competition $[17,18,19]$. In contrast, in the UAMN, better blood supply in skin, allows the maintenance of follicles, which leads to a reduction in the diameter of fibers, maintaining the same weight of fleece [22,23,28,29].

The weight of fleece was similar in both breeds (3.0 vs $3.4 \mathrm{~kg}$; p>0.05). However, the DMN has a larger fiber diameter than the UAMN ( $\mathrm{p}<0.05)$, being 14.6 vs. $19.4 \mu \mathrm{m}$, respectively. This could be associated with the greater competition between follicles in UAMN genotypes [30,31], which determiner a small amount of nutrients supplied to each follicle.

The percentage of fibers greater than 30 microns find as expected significant differences between genotypes, being higher this percentage in the genotype DMN $(0.15$ versus $0.52, p=0.06)$. In UAMN these results show a tendency to have a lower percentage of individual thick fibers (greater than 30 microns) and are usually reported as comfort factor, the percentage of wool fibers with a fiber diameter less than 30 microns [17].

CFY showed significant differences between genotypes ( $\mathrm{p}<0.05)$, with higher yield in UAMN (76.6 vs. $72.4 \%)$. Bearing in mind that UAMN has a smaller fiber diameter than DMN this difference was not expected since according to previous data from Sanjurjo [32], they found that as the average diameter of fibers is greater the production of greasy decreases and as a consequence increases the CFY.

\section{Conclusion}

Associations found between the S/P ratio and the main characteristics of wool evaluated in this work are medium to low. As relevant data, they indicate that the correlation between follicular density and diameter is moderate and negative.

The UAMN genotype shows an increase in the S/P ratio between two and nine months of age. However, in the DMN genotype, there is no such increase. In the percentage of secondary follicles derived no interaction effect was found under any evaluated case. The higher follicular density is explained in the UAMN, by a significant follicular maturation in the second wave. In contrast, follicular regression is observed in DMN, feasible due to poor follicle nutrition due to high competition. Instead, in the UAMN, better blood supply in your skin, allows the maintenance of the follicles, which leads to a reduction in the diameter of fibers, maintaining the same weight of fleece.

In the UAMN genotype the FD and SL are positively associated with the CFW. DF shows a high positive relationship with LM, which does not match the literature. This can be explained by the selection made on the WF trait, which by not increasing the number of follicles per skin area would boost the efficiency of conversion into fiber thus increasing the staple length.

It has been difficult in the past to get heavy and thin fleeces due to the positive association that exists between diameter and, so the S/P ratio could be of great help in obtaining thinner fleece and that do not have a significant drop in weight. Therefore, it is demonstrated in this work that animals with higher follicular densities, especially secondary follicles, will have smaller fiber diameters. This explained by follicular competition, at higher density greater competition for nutrients. This was confirmed by observing the low and negative selection tool in the finest animals, follicular density.

In view of the above, based on this work and those considered here it can be concluded with these results obtained that by selecting for greater S/P ratio will obtain fleeces with less fiber diameter, which induces that in the present and in the future it can be used as a valid selection criterion to decrease the diameter. 


\section{Compliance with ethical standards}

\section{Acknowledgments}

Firstly, we acknowledge Ignacio de Barbieri and Ricardo Rodriguez Palma for some technical support. Secondly, to the field staff of the Glencoe Experimental Unit of INIA Tacuarembó.

\section{Disclosure of conflict of interest}

The authors declared no potential conflicting of interest with respect to the research, authorship and/or publication of this article.

\section{References}

[1] Montossi F, de Barbieri I, Ciappesoni G, Ganzabal A, Banchero, G, Luzardo S, San Julian R. Intensification, diversification, and specialization to improve the competitiveness of sheep production systems under pastoral conditions: Uruguay's case. Animal Front. 2013; 3:28-35.

[2] De Barbieri I, Ramos Z, Montossi F. Superfine Wool: a joint path of research, transfer and production. Montevideo, Uruguay. INIA Technical Series. 2018; 242: 43.

[3] Cardellino R. The Production of Superfine Merino Wool in Uruguay; an excellent project with positive and measurable results over the last two decades. DELTA Consultants in Animal Production, Montevideo, Uruguay. $2020 ; 1-7$.

[4] Kotzé, J.J.J., 1951. The development of a mutton-woolled sheep for the sour-grassveld area. Farming in South Africa April 1951, 110-113.

[5] Montossi F, de Barbieri I, Ciappesoni G, San Julián R., Luzardo S, Martínez H, Frugoni J, Levratto J. New genetic options for the sheep sector in Uruguay: evaluation of crosses with Merino Dohne. In: INIA Uruguay Journal. 2007; 10: 6-92.

[6] Montossi F, de Barbieri I, Ciappesoni G, Ravagnolo O, DE Mattos D, Pérez Jones J, Fros A, Grattarola M, Mederos, A, Soares de Lima M. Foundational nucleus of fine and superfine merino of the experimental unit "GLENCOE" INIA Uruguay: an innovative experience of associative and participatory genetic improvement. AGROCIENCE. 2005; IX: 609- 616.

[7] Carter HB, Clarke WH. Hair follicle group and skin follicle population of Australian Merino Sheep. Australian Journal Research. 1957; 8(1): 91-108.

[8] McCloghry CE. Alternative dye banding method for measuring the length growth rate of wool in sheep. New Zealand Journal of Agricultural Research. 1997; 40:569-571.

[9] Maddocks LG, Jackson N. Structural studies of sheep cattle and goat skin. CSIRO Research. 1988; 57-65.

[10] Ministry of Livestock, Agriculture and Fisheries. Uruguay. 2019.

[11] McCloghry CE, Brown GH, Uphill GC. Computer-assisted imagine analysis for measurement of wool follicle density and fibre diameter in skin sections. New Zealand Journal of Agricultural Research. 1997; 40:239-244.

[12] Vallejo A. Study of the hair follicular population of the progeny of Australian Merino sheep with different characteristics in their skin and fleece inseminated with MPM (Multipurpose Merinos) rams. Thesis Ing. Agr. Montevideo, Uruguay. Agronomy Faculty. 2011; 101p.

[13] Ramos Z, Blair T, De Barbieri I, Ciappesoni G, Montossi Fy, Kenyon R. Phenotypic Responses to Selection for Ultrafine Wool in Uruguayan Yearling Lambs. Agriculture. 2021; 11: 179p.

[14] Gómez M, Regalado A, Stirling E. Phenotypic correlations between the hair follicular population and quality characteristics of sheep and sheep wool from the Fino Merino Nucleus. Thesis Ing. Agr. Montevideo, Uruguay. Agronomy Faculty.2004; 115p.

[15] Li L, Godwin I, Liu SM, Oddy VH, Nolan JV. Skin characteristics and skin protein composition of Merinos differing in estimated breeding values for wool growth and fed at above and below maintenance. Australian Journal of Experimental Agriculture. 2005; 46(7):937-941. 
[16] Lyne AG. The postnatal Development of Wool Follicles, Shedding and Skin Thinkness in Inbred Merino and Southdown-Merino Crossbred Sheep.. Australian Journal of Biological Sciences. 1961; 14(1): 141-156.

[17] Nancarrow MJ, Nagorcka BN, Purvis IW. Skin and follicle attributes contribute to differences in clean fleece weight in superfine Merino sheep. Animal Production in Australia. 1998; 22:253-256.

[18] Williams AJ, Winston RJ. A study of the characteristic of wool follicle and fibre in Merino sheep genetically different in wool production. Australian Journal of Agricultural Research. 1987; 38:743-755.

[19] Ryder ML, Stephenson SK. Wool growth. London, Academic Press. 1968; 805p.

[20] Schinckel PG y, Short BF. The influence of nutritional level during pre-natal and early post-natal life on adult fleece and body characters. Australian Journal of Agricultural Research. 2001; 12:176-202.

[21] Tuner HN, Young SSY. Quantitative Genetics in Sheep Breeding. Cornell University, Ithaca, New York. 1969; 134137.

[22] Black JL. Mechanisms controlling de rate of growth, composition and morphology of wool in merino improvement programs in Australia. In: National Symposium NSW (1987, Leura, Australia). Proceedings. Melbourne, Australian Wool Corporation. 1987; 189-206.

[23] Williams AJ, Thornberry KJ. The skin thickness of medium wool Merino sheep and its relationship to wool production. Proceedings of the Australian Society of Animal Production. 1992; 19: 138-141.

[24] Chapman RE. A comparison of the effects of some defleecing skin of sheep. In: Hudson PRW (ed) compounds on wool follicles, fibres and Wool harvesting skin of sheep. In: Hudson PRW (ed)research and development. Aust Wool corp. Melbourne. 1980; 271-286.

[25] Hynd PI, Ponzoni RW, Grimson R, Jaensch KS, Smith D, Kenyon R. Wool follicle and skin characters-their potential to improve wool production and quality in Merino sheep. Wool Technology and Sheep Breeding. 1996; 44(3):167-177.

[26] Williams AJ, Winston RJ. A study of the characteristic of wool follicle and fibre in Merino sheep genetically different in wool production. Australian Journal of Agricultural Research. 1987; 38: 743-755.

[27] Van Wyk JB, Swanepoel JW, Delport GJ, Cloete SWP. Across flock genetic parameters estimation for yearling body weight and fleece traits in the South African Dohne Merino population. South African Journal of Animal Science. 2008; 38(1):31-37.

[28] Reis JP. Length growth and diameter relationships of Merino wool fibres. Wool Technology and Sheep Breeding. 1982; 40(2):52-55.

[29] Corbett JL. Variation in wool growth with physiological satate. In Physiological and environmental limitations to wool growth. Eds J. l. Black y P J. Reis. Armindale. University of New England. 1979; 79p.

[30] Hynd PI, Schlink AC, Phillips PM, Scobie DR. Mitotic activity in cells of the wool follicle bulb. Australian Journal of Biological Sciences. 1986; 39(4):329-340.

[31] Fraser AS, Short BF. The Biology of the Fleece. CSIRO. Melbourne. 1960; 113p.

[32] Sanjurjo P. Phenotypic correlations between the hair follicular population and quality characteristics of sheep and sheep line of 3 herds of the Merino Fino Project. Thesis Ing. Agr. Montevideo, Uruguay. Agronomy Faculty.2005; 173p. 